\title{
Outcomes of External-Beam Radiation Therapy Boost with Conventional Fractionation in Cervical Cancer: A Retrospective Analysis about 133 Cases
}

\author{
Evrard Narcisse Séka1, Bertrand Ghislain Compaoré1, Bassané Alain Wilfried Mossé1, \\ Siham Jaba', Kouadio Davy N'chiépo', Maroua Benlemlih', ${ }^{1,2}$, Hasnae Bouhia', \\ Mohammed Adnane Tazi ${ }^{3}$, Sanae El Majjaoui1,4, Noureddine Benjaafar',4 \\ ${ }^{1}$ Department of Radiotherapy, National Institute of Oncology, Rabat, Morocco \\ ${ }^{2}$ Department of Radiotherapy, Mohammed V Military Hospital, Rabat, Morocco \\ ${ }^{3}$ National School of Public Health, Rabat, Morocco \\ ${ }^{4}$ Mohammed V University in Rabat, Rabat, Morocco \\ Email:docsena2810@gmail.com
}

How to cite this paper: Séka, E.N., Compaoré, B.G., Mossé, B.A.W., Jaba, S., N'chiépo, K.D., Benlemlih, M., Bouhia, H., Tazi, M.A., El Majjaoui, S. and Benjaafar, N. (2020) Outcomes of External-Beam Radiation Therapy Boost with Conventional Fractionation in Cervical Cancer: A Retrospective Analysis about 133 Cases. Journal of Cancer Therapy, 11, 547-560.

https://doi.org/10.4236/jct.2020.119047

Received: August 12, 2020

Accepted: September 22, 2020

Published: September 25, 2020

Copyright $\odot 2020$ by author(s) and Scientific Research Publishing Inc. This work is licensed under the Creative Commons Attribution International License (CC BY 4.0).

http://creativecommons.org/licenses/by/4.0/ (c) (i) Open Access

\begin{abstract}
Introduction: External-beam radiation therapy boost is a treatment option in cervical cancer when brachytherapy is not feasible. Though less effective than brachytherapy, some encouraging results have been reported from some institutions experiences. We conducted this study to assess outcomes of EBRT boost for our patients at National Institute of Oncology in Rabat. Patients and Methods: We collected data from patients treated for cervical cancer between January 2012 and December 2015. Patients, tumor and treatment characteristics were collected. Overall survival (OS), disease-free survival (DFS) and prognostic factors influencing DFS were assessed. Results: One hundred and thirty-three patients were enrolled. Median age was 52 years. Patient haemoglobin level ranged from 3.9 to $15.5 \mathrm{~g} / \mathrm{dl}$ [mean: $11.2 \mathrm{~g} / \mathrm{dl}$ ]. Most tumors were classified stage III/IVA (63.2\%) according to the FIGO classification. Regional lymph node metastases (pelvic and or para-aortic) were observed in $45.1 \%$. Median total dose to tumor was $69.6 \mathrm{~Gy}$ (ranging from 66 to $70 \mathrm{~Gy}$ ). Overall treatment time was protracted, with a median of 60 days. Most of patients received concurrent chemotherapy (94.7\%) and the number of cycle ranged from 2 to 7 (median $=5$ ). The follow-up median was 31.3 months, ranging from 6.2 to 96.8 months. At the first visit, most patients achieved complete response (80.5\%). Five years OS and DFS were $47 \%$ and $44 \%$ respectively. In univariate and multivariate analysis, regional lymph nodes metastasis (presence or absence) and haemoglobin level $(\leq 11 \mathrm{~g} / \mathrm{dl}$
\end{abstract}


and $>11 \mathrm{~g} / \mathrm{dl})$ were the two significant and independent prognostic factors influencing DFS (HR: 1.86; $\mathrm{p}=0.01$ for the former) (HR: $0.59 ; \mathrm{p}=0.03$ for the latter). Conclusion: Our study showed that EBRT boost in conventional fractionation was an acceptable treatment option for cervical cancer unamenable to brachytherapy, especially in the two subgroups of patients that are those without pelvic and/or para-aortic lymph node metastasis and those with haemoglobin level above $11 \mathrm{~g} / \mathrm{dl}$.

\section{Keywords}

Cervical Cancer, External Beam Radiation Therapy Boost, Survival, Prognostic Factors

\section{Introduction}

Concurrent chemoradiotherapy followed by intracaviatry brachytherapy is the mainstay of the treatment of locally advanced cancer of the cervix [1]. The treatment, generally, follows two steps. Firstly, External-Beam Radiation Therapy (EBRT) is used to give a radiation dose ( 45 to $50 \mathrm{~Gy}$ ) to a large volume that includes whole the genital tract and regional lymph node areas. This, obviously, will result in tumor shrinkage. Secondly, brachytherapy is used to deliver a high dose in a reduced and limited tumor volume (boost dose) [1] [2]. The goal is to attain a high total dose in the tumor (up to 85 or $90 \mathrm{~Gy}$ ). However, in some situations, brachytherapy can be either not feasible or not available. Therefore, using EBRT only for the whole treatment course constitutes an acceptable option. In the last two decades, some institutions have published the results of their practices. Although it is known that the EBRT boost resulted in fewer outcomes than brachytherapy, some encouraging results had been reported [3] [4] [5].

According to GLOBOCAN 2018 statistics, cervical cancer is the second most common malignancy in women in Morocco. In 2018, 3388 new cases and 2465 death were registered in the country. It is the second cancer leading cause of death in women [6]. The National Institute of Oncology is the referral hospital of adult and solid malignancy in the Rabat district. Many cervical cancers, especially the locally advanced, are treated each year in the department of radiotherapy of our institution. No study has previously addressed the concern of EBRT boost in cervical cancer. Therefore, we conducted this study to assess outcomes of our practice and determine prognostic factors associated with survival in cervical cancer treated with EBRT boost.

\section{Patients and Methods}

\subsection{Patients' Selection}

This study is a retrospective one. Data were collected from patients treated for cervical cancer in the department of radiotherapy of NIO (National Institute 
Oncology) from January 2012 to December 2014. We included patients that had the following criteria: newly diagnosed and histologically confirmed cervical cancer, no distant metastasis apart from para-aortic lymph nodes, no history of gynaecologic malignancy, and no history of pelvic radiation therapy. Patients treated with surgery or brachytherapy were excluded from the study. Tumors were staged according to the International Federation of Gynaecologists and Oncologists (FIGO) staging system, after a workup that included gynaecologic examination and thorax-abdomen-pelvic CT-scan or pelvic MRI plus thorax-abdomen CT-scan. Complete blood cells count and kidney function assessment (urea, creatinine, and clearance) were obtained for all patients. Patients treated by EBRT boost were selected based on two manners:

- After the whole pelvic radiation therapy (WPRT) course, if brachytherapy or surgery was not feasible, the treatment was completed by the EBRT boost.

- At the initial evaluation, some patients with very large and extensive tumors were selected, at the physician discretion, to receive an EBRT boost immediately after the whole pelvic radiation therapy (WPRT) course.

\subsection{Treatment Description}

The treatment plan used a 3-Dimensional Conformal Radiation Therapy (3DCRT) technique for all cases. All patients had a 3D CT-scan (3Dimensional Computed Tomography scan) simulation in supine position, arms above the chest, empty rectum, and a full bladder. CT slices thickness was $5 \mathrm{~mm}$. Intravenous contrast enhancement was mandatory and realized for all patients who had no kidney dysfunction.

Whole Pelvic Radiation Therapy (WPRT) field covered the gross primary tumor, the total genital system (cervix, uterine corpus, vaginal portion, parametria, and adnexa) and the regional pelvic node areas, including the common, internal and external iliac, obturator and presacral lymph nodes. The field was extended to cover para-aortic lymph nodes if patients had para-aortic lymph node metastasis. EBRT boost volume included primary tumor, cervix, uterine corpus, bilateral parametria, and a portion of vagina. Patients were not re-simulated after WPRT; the same treatment plan was used for both the WPRT and the boost. A 7 - $10 \mathrm{~mm}$ geographical margin was added to the volume described above to obtain the planning target volume. Radiation therapy was delivered in conventional fractionation ( 1.8 or $2 \mathrm{~Gy} /$ fraction and 5 fractions per week) with a linear accelerator (ELEKTA SYSTEM ${ }^{\mathrm{R}}$ ). Traditional four-field «in box» technique (with anteroposterior/posteroanterior and two opposed laterals) was used for both WPRT and boost.

Concurrent chemotherapy was administered during the whole treatment course whenever it was possible. The regiment used was intravenous infusion of cisplatin $40 \mathrm{mg} / \mathrm{m}^{2}$ (maximal dose $=70 \mathrm{mg}$ ) once a week during the total radiotherapy course (WPRT course and Boost course). Before each cisplatin cycle, general condition evaluated with the grading system of the WHO (World Health 
Organization) performance status, blood cells count and renal clearance were evaluated or performed. The cycle was precluded if patients had PS grade 3 or 4, haemoglobin level below $8 \mathrm{~g} / \mathrm{dl}$, granulocytes number less than $1500 / \mathrm{mm}^{3}$, platelet number $<100,000 / \mathrm{mm}^{3}$ or creatinine clearance $<60 \mathrm{ml} /$ minute.

\subsection{Follow-Up}

Patients were examined every 3 or 4 months during the first 2 years after completing treatment, thereafter every 6 months for the 3 subsequent years, then annually. Treatment response, disease recurrence, and complications were recorded. Tumor response was assessed using clinical examination. Imaging was not performed systematically. An MRI or CT-scan was required for patients who presented suspicious symptoms. All recurrences were histologically confirmed if the site was accessible for biopsy.

\subsection{Survival and Statistical Analysis}

The endpoints of our study included disease-free survival (DFS) and overall survival (OS). DFS was calculated from the date of the start of treatment to the date of any sign of tumor relapse may it be local, regional or remote. The OS was calculated from the date of the beginning of treatment to the day of death (of any cause); any patient loss of follow-up after failure or disease progression was assumed dead from the disease.

Survivals were estimated by the Kaplan-Meier method. Predictor variables, including age, general condition, tumor size (the greatest axis measurement), lymph node metastasis, number of concurrent chemotherapy cycles, haemoglobin level (measured at diagnosis, before any treatment or blood transfusion) and overall treatment time (OTT), were analyzed to assess their impact on disease control. The differences in DFS in univariate analysis were assessed with the log-rank test. For multivariate analysis, a Cox proportional hazards model was developed using forward stepwise regression for all variable showing a trend $(p<0.15)$ on univariate analysis. Results were considered significant for $p$ values less than 0.05 .

\section{Results}

According to our eligibility criteria, 133 patients were enrolled in the study. Patients' ages varied from 26 to 83 years and the median was 52 years. Tumors were overwhelmingly squamous cell carcinomas (91.7\%) followed by adenocarcinomas (6\%). The others subtypes were adenosquamous carcinoma (2 patients) and small cell carcinoma (1 patient). Tumors in our study are relatively large with a median size of $6 \mathrm{~cm}$. Tumors were staged according to the FIGO staging system as stage I (1.5\%), stage II (35.3\%), stage III (55.6\%) and stage IVA (7.6\%). Regional lymph node metastases (pelvic and or para-aortic) were observed in 60 patients (45.1\%). In 46 patients (34.6\%) they were pelvic only and in 14 patients (10.5\%) they were para-aortic $+/-$ pelvic. Haemoglobin level had been reported in 125 patients $(94 \%)$, and values varied from $3.9 \mathrm{~g} / \mathrm{dl}$ to $15.5 \mathrm{~g} / \mathrm{dl}$ (median = 
$11.2 \mathrm{~g} / \mathrm{dl})$. Of them, forty-six $(36.8 \%)$ had levels below or equal to $11 \mathrm{~g} / \mathrm{dl}$ and seventy-nine (63.2\%) had levels above $11 \mathrm{~g} / \mathrm{dl}$. In eight patients (6\%), haemoglobin values were not available. Patients, tumors and treatment characteristics are shown in Table 1.

Table 1. Patients and tumor characteristics.

\begin{tabular}{|c|c|}
\hline Parameters & Values \\
\hline \multicolumn{2}{|l|}{ Age } \\
\hline Median (range) & $52[26-83]$ \\
\hline \multicolumn{2}{|l|}{ WHO PS } \\
\hline 0 & $47(35.4 \%)$ \\
\hline 1 & $78(58.6 \%)$ \\
\hline 2 & $8(6 \%)$ \\
\hline \multicolumn{2}{|l|}{ Histological subtype } \\
\hline $\mathrm{SCC}^{\mathrm{b}}$ & $122(91.7 \%)$ \\
\hline Adenocarcinoma & $8(6 \%)$ \\
\hline Others & $3(2.3 \%)$ \\
\hline \multicolumn{2}{|l|}{ Tumor size } \\
\hline Median (range) & $6[3-13]$ \\
\hline \multicolumn{2}{|l|}{ RLN $^{c}$ metastasis } \\
\hline Absence & $73(54.9 \%)$ \\
\hline Pelvic only & $46(34.6 \%)$ \\
\hline Lombo-aortic $+/$ - Pelvic & $14(10.5 \%)$ \\
\hline \multicolumn{2}{|l|}{ FIGO stage } \\
\hline I-II & $49(36.8 \%)$ \\
\hline III-IVA & $84(63.2 \%)$ \\
\hline \multicolumn{2}{|l|}{$\mathrm{Hb}^{\mathrm{d}}$ level } \\
\hline Median (range) & $11.2[3.9-15.5]$ \\
\hline \multicolumn{2}{|l|}{ Total dose to the tumor } \\
\hline Mean (range) & $69.6[66-70]$ \\
\hline \multicolumn{2}{|c|}{ Use of concurrent chemotherapy } \\
\hline Yes & $126(94.7 \%)$ \\
\hline No & $7(5.3 \%)$ \\
\hline \multicolumn{2}{|c|}{ Overall treatment time (in days) } \\
\hline Median & $60[49-109]$ \\
\hline \multicolumn{2}{|c|}{ Response to treatment (at the first follow-up visit) } \\
\hline Complete & $107(80.5 \%)$ \\
\hline Partial & $18(13.5 \%)$ \\
\hline Progression & $8(6 \%)$ \\
\hline
\end{tabular}

a्aerformance Status; ${ }^{\mathrm{b}} \mathrm{S} q u a m o u s$ cell Carcinoma; ${ }^{\mathrm{C}}$ Regional lymph node; ${ }^{\mathrm{d}} \mathrm{Haemoglobin}$. 
Reasons for being unable to perform brachytherapy were determined in 113 patients (Table 2). In most cases ( 71 cases), these were tumor-related reasons: 26 patients had locally extensive disease involving neighbouring structures; and 45 patients had a large residual disease or vagina wall involvement after WPRT. Five patients were unfit for anaesthesia. In the other 20 patients, brachytherapy was not available. In 20 patients, reasons could not be determined.

All patients were treated with conventional fractionation. The total doses were 70 Gy in 116 patients (87.2\%), 68 Gy in 7 patients (5.3\%), and 66 Gy in 10 patients (7.5\%). Most of patients received concurrent chemotherapy (94.7\%). The number of chemotherapy cycle was not reported in 11 patients. In 115 patients, the number of cycle was available and ranged from 2 to 7 with a median of 5 (69 patients received 5 cycles or less and 46 patients received more than 5 cycles). The follow-up median was 31.32 months, ranging from 6.2 to 96.8 months. At the first visit, most patients (107) had complete responses whereas 18 and 8 patients had residual and progressive disease respectively.

During follow-up, 60 patients (54.11\%) experienced disease recurrences. Patterns of recurrences are listed in Table 3.

The 5-years' overall survival (OS) and disease-free survival (DFS) were $47 \%$ ( median $=49.15$ months) and 44\% (median $=28.49$ months) respectively (Figure 1 and Figure 2). The prognostic effects of variables on DFS were presented

Table 2. Reasons for not underwent brachytherapy.

\begin{tabular}{cc}
\hline Reasons $(\mathrm{n}=133)$ & Values \\
\hline $\begin{array}{c}\text { Anatomic reasons (narrow or conical vagina and } \\
\text { cervix ostium not visualized) } \\
\text { Patients unfit for anaesthesia } \\
\text { Large residual disease or vagina wall involvement } \\
\text { Locally extensive disease } \\
\text { Brachytherapy not available }\end{array}$ & $5(3.8 \%)$ \\
Unknown & $45(33.8 \%)$ \\
\end{tabular}

Table 3. Patterns of tumor recurrence.

\begin{tabular}{cc}
\hline Patterns of recurrence $(\mathrm{n}=60)$ & Values \\
Locoregional (local + pelvic LN) & $28(46.5 \%)$ \\
PALN $^{\text {a }}+/$ - locoregional & $6(10 \%)$ \\
Metastatic only & $9(15 \%)$ \\
Metastatic +/- locoregional & $8(13.3 \%)$ \\
\end{tabular}




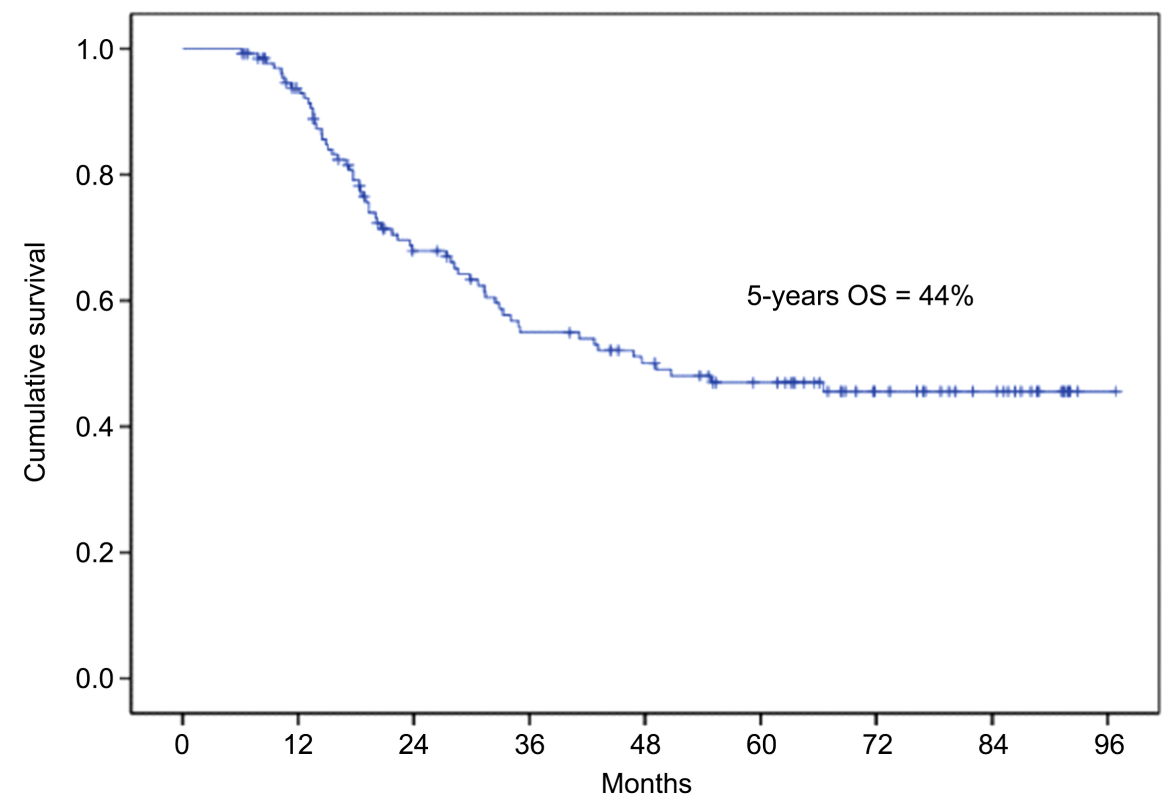

Figure 1. Five-years overall survival curve.



Figure 2. Disease-free survival curve.

in Table 4. On univariate analysis, haemoglobin level and regional lymph nodes (RLN) metastasis influenced significantly the 5-years DFS (Figure 3 and Figure 4). Patients who had haemoglobin levels above $11 \mathrm{~g} / \mathrm{dl}$ had significant higher 5 -years survival (DFS) than those with haemoglobin less than $11 \mathrm{~g} / \mathrm{dl}(49.7 \%$ vs 29.0\%; $\mathrm{p}=0.017$ ) and patients who had no RLN metastasis showed significant higher 5-years survival than those with RLN metastasis $(53.8 \%$ vs $32.1 \%$; $\mathrm{p}=$ 0.007). On multivariate analysis, both absence of RLN metastasis $(\mathrm{p}=0.03 ; \mathrm{HR}=$ 0.59; CI: [0.37 - 0.96] and haemoglobin level above $11 \mathrm{~g} / \mathrm{dl}(\mathrm{p}=0.01$; $\mathrm{HR}=1.86$; CI: [1.15 - 2.99] were independent prognostic factors associated with better DFS. 
In most cases, treatment was well tolerated (88\%). Sixteen patients $(12 \%)$ experienced late treatment toxicities described as rectal bleeding ( 5 patients), haematuria and/or dysuria (8 patients), and combination of rectal bleeding and haematuria and dysuria ( 2 patients). These late toxicities were grade 1 in 6 cases, grade 2 in 8 cases, and grade 3 in 2 cases. There was no grade 4 toxicity.

Table 4. Univariate and multivariate analysis of prognosis variables for DFS.

\begin{tabular}{|c|c|c|c|c|c|}
\hline \multirow{2}{*}{$\begin{array}{c}\text { Variables } \\
\text { (number of case) }\end{array}$} & \multirow{2}{*}{$\begin{array}{c}5 \text {-years } \\
\text { DFS (\%) }\end{array}$} & \multicolumn{2}{|c|}{$p$-value } & \multirow[b]{2}{*}{$\mathrm{HR}^{\mathrm{a}}$} & \multirow[b]{2}{*}{$95 \% \mathrm{CI}^{\mathrm{b}}$} \\
\hline & & $\begin{array}{l}\text { Univariate } \\
\text { analysis }\end{array}$ & $\begin{array}{c}\text { Multivariate } \\
\text { analysis }\end{array}$ & & \\
\hline Age & & 0.92 & - & & \\
\hline$\leq 52(70)$ & 44.5 & & & - & - \\
\hline$>52(63)$ & 43.7 & & & - & - \\
\hline WHO PS & & 0.48 & - & & \\
\hline $0(47)$ & 48.6 & & & - & - \\
\hline $1-2(86)$ & 41.4 & & & - & - \\
\hline Hb level & & 0.017 & 0.03 & & \\
\hline$\leq 11(46)$ & 29.0 & & & 1 & - \\
\hline$>11(79)$ & 49.7 & & & 0.59 & {$[0.37-0.96]$} \\
\hline Unknown (8) & - & & & - & - \\
\hline Tumor size & & 0.19 & - & & \\
\hline$\leq 6(88)$ & 47.7 & & & - & - \\
\hline$>6(45)$ & 36.5 & & & - & - \\
\hline FIGO stage & & 0.19 & - & & \\
\hline I/II (49) & 49.7 & & & - & - \\
\hline III/IVA (84) & 39.9 & & & - & - \\
\hline $\mathrm{RLN}^{\mathrm{c}}$ metastasis & & 0.007 & 0.01 & & \\
\hline No (73) & 53.8 & & & 1 & - \\
\hline Yes (60) & 32.1 & & & 1.86 & [1.15 - 2.99] \\
\hline CCT cycles & & 0.86 & - & & \\
\hline$\leq 5(69)$ & 49.0 & & & - & - \\
\hline$>5(46)$ & 47.0 & & & - & - \\
\hline Unknown (11) & - & & & - & - \\
\hline OTT & & 0.37 & - & & \\
\hline$\leq 60$ & 38.4 & & & - & - \\
\hline$>60$ & 48.4 & & & - & - \\
\hline
\end{tabular}

${ }^{\mathrm{a}}$ Hazard ratio; ${ }^{\mathrm{b}}$ Confidence interval; ${ }^{\mathrm{C}}$ Regional lymph nodes. 


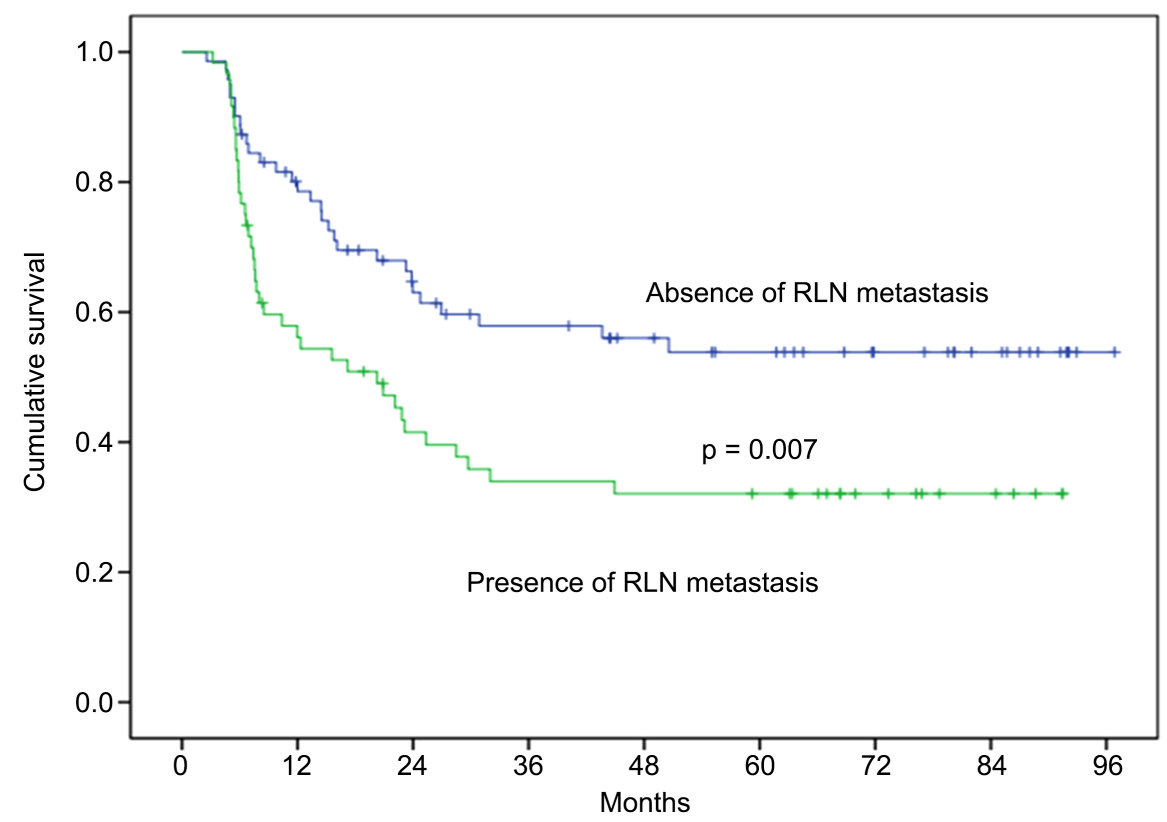

Figure 3. DFS curves according to regional lymph node.

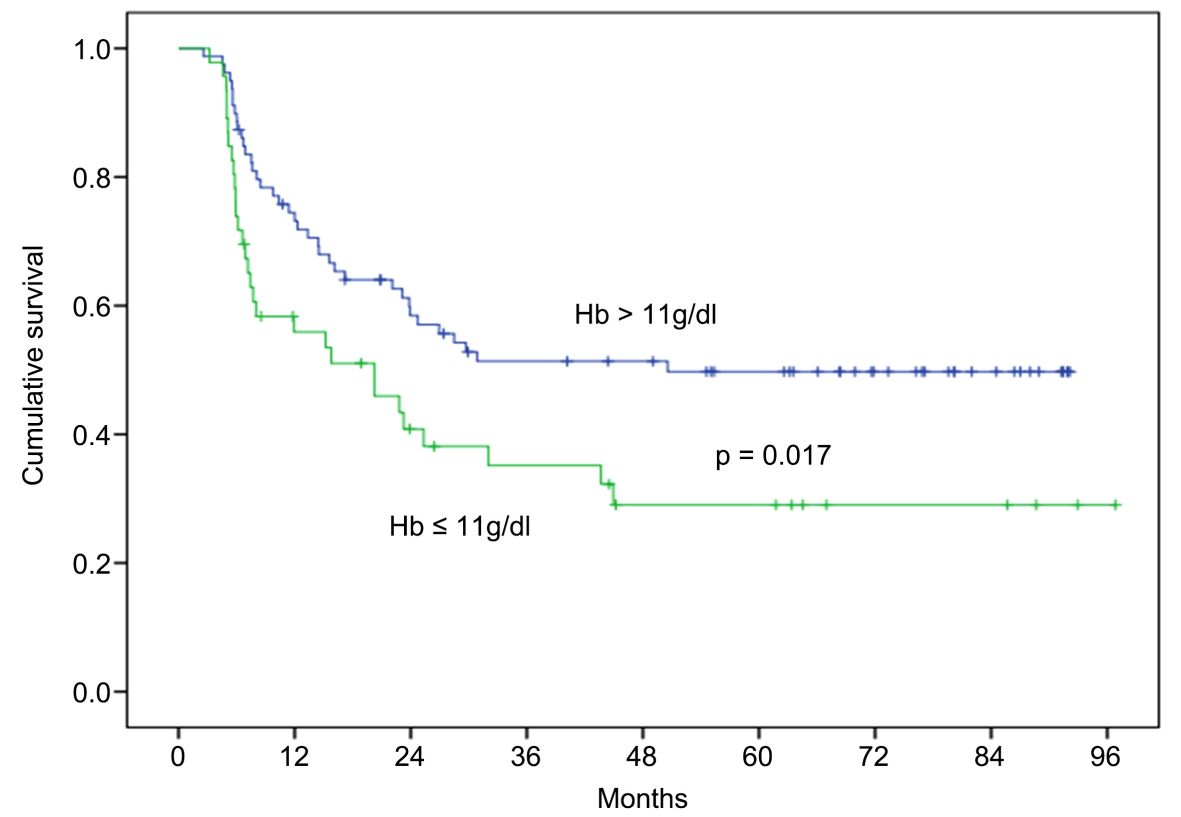

Figure 4. DFS curves according to haemoglobin level.

\section{Discussion}

Our study was a retrospective one that aimed overall survival, disease-free survival, and predictive factors associated with survival in patients with cervical cancer treated with EBRT boost. All patients in this study were treated with 3DCRT in conventional fractionation. Although most of our patients experienced disease recurrence within 5 years following treatment, data from our study demonstrated that the EBRT boost in conventional fractionation was a reasonable treatment approach when brachytherapy is precluded. About eighty 
percent of our patients achieved local control three months after the end of the treatment, 5 years' overall survival and disease-free survival were $47 \%$ and $44 \%$ respectively.

During the past two decades, many authors have documented results of the use of EBRT alone in patients in those brachytherapy was not possible [3] [4] [5] [7] [8] [9] [10]. Although it is known that the absence of brachytherapy leads to less favourable outcomes, some authors found that the EBRT boost could lead to encouraging results in certain subgroups of patients [3] [4] [5]. Barraclough et al. reported $49.3 \%$ for the 5 years' overall survival [3]. In Haeyong et al. study the DFS and OS were $54.7 \%$ and $75 \%$ respectively [5]. Mastsuura et al. reported that 3 years' local control and overall survival were $75 \%$ and $43.8 \%$ respectively [4]. Apart from the absence of brachytherapy, others tumor characteristics can influence treatment results. These characteristics include patient age and general condition (WHO performance status), tumor size and stage, haemoglobin level, regional lymph nodes status, and overall treatment time OTT. Saibishkumar et al. found that the response to EBRT was the significant factor associated with better DFS and OS [7]. According to Haeyoung et al., achieving complete treatment response at a first follow-up visit and shorter OTT were both significantly associated with favourable local failure-free survival [5]. In Kei et al. study, FIGO stage and tumor size were the significant factors associated with survival [8]. In our study, patients having tumor size equal or less than $6 \mathrm{~cm}$, FIGO stage I/II and overall treatment time more than 60 days, had better DFS than their counterparts (size $>6 \mathrm{~cm}$, FIGO stage III/IV and OTT $\leq 60$ days) but the differences were not significant.

Haemoglobin level and regional lymph node metastasis have emerged as the two significant and independent prognostic factors. Haemoglobin level and tumor size are two characteristics reflecting tumor oxygenation that is a main radiobiology parameter influencing tumor sensitivity to radiation. Anaemia results in less oxygenation of the tumor, and the bulky tumor is characterized by increased ischemic and necrotic areas. Small tumors are the most oxygenated and are more sensitive to radiation. Conversely, large tumors, in which many ischemic and necrosis areas occur, are less sensitive. Consequently, these large tumors benefit from fractionation, as progressive tumor-shrinking results in progressive re-oxygenation of ischemic areas. Therefore, fractionation can overcome the tumor size effect. Anaemia, conversely, have a permanent effect. Blood and oxygen supplies are permanently reduced, creating a "chronic hypoxia" state that cannot be overcome by fractionation. Low haemoglobin level is also worsened, in the time, with chemotherapy due to hematologic toxicity. Many authors had previously demonstrated that a low haemoglobin level was associated with bad outcomes [11] [12] [13]. Theoretically, blood transfusion can restore blood and oxygen supplies, but studies that focused on the effect of transfusion are conflicting [14] [15] [16].

The second predictive factor is lymph node metastasis. The presence of pelvic 
and/or PALN metastasis was associated with worse DFS, in our study. The significance of lymph node metastasis in prognosis is a well-established parameter in TNM staging system. Some studies have demonstrated the prognostic value of pelvic or and para-aortic lymph nodes involvement in cervical cancer, so that the last FIGO system classification (2018) created the IIIC group that corresponds to the involvement of pelvic or PALN [17] [18] [19].

Ultimately, we can conclude that prognosis in locally advanced cervical cancer unamenable to undergo brachytherapy is related to tumor extent (reflected by the local extent and regional lymph node involvement) and tumor oxygenation (reflected by haemoglobin level and tumor size).

In the new radiotherapy era, some studies addressed the role of high conformal radiotherapy technics such as intensity-modulated radiation therapy (IMRT) and stereotaxic body radiation therapy (SBRT) in management of cervix cancer [1] [20] [21] [22]. SBRT, especially, delivers a very high dose in a small volume within a short time period. This is an interesting option as it mimics HDR (high dose rate) brachytherapy. When considering the high $\alpha / \beta$ ratio (about 10) of cervical cancer, one can predict that a large fraction size could not be advantageous radiobiologically. Nevertheless, the physiopathology of high dose per fraction shows some advantages: hypoxic cell resistance is overcome as cell death is predominantly due to tumor microvasculature damage. Endothelial cells death under the effect of a high dose is not related to DNA damage but to the initiation of apoptosis via the ceramides pathway after cell membrane damage. Besides, tumor recurrence is slower through the disturbance of revascularization mechanisms [23]. Studies showed promising results with these techniques [1] [21] [22]. Therefore, they should be considered for boost dose delivering in patients with cervical cancer unamenable for brachytherapy.

The use of pelvic field irradiation in all the patients except those with overt para-aortic lymph nodes metastases might be regarded as a limitation of this study. This attitude, certainly, has led to undertreat some high-risk patients harbouring occult metastases in para-aortic lymph nodes. In our institution, the practice is founded on the results of the RTOG 90-01 trial. This trial indicated that concurrent chemotherapy with pelvic RT led to significant OS and DFS improvements over extended-field EBRT in patients with FIGO stages IIB to IVA disease (plus stages IB to IIA tumors $5 \mathrm{~cm}$ or larger or biopsy-proven pelvic nodal metastases) [24] [25]. However, extended-field RT was used without concurrent chemotherapy in this trial. The question of whether prophylactic extended-field RT (PEFRT) in addition to systemic chemotherapy would provide additional therapeutic gain is not overtly answered until now. Nevertheless, some recent studies demonstrated the benefit of PEFRT in the high-risk patients [26] [27]. In our study, 46 patients (34.6\%) had positive pelvic lymph node disease. They did not receive PEFRT. This would have led to increase the para-aortic and distant recurrence rate. However, most of the recurrences were depicted in the treatment field (local and/or pelvic LN recurrence). Other remark- 
able fact is that the sites of the pelvic lymph node, the number and the size of these pelvic lymph nodes were not precisely described. Therefore, it was impossible to identify patients at high risk that would have relapse in absence of para-aortic prophylactic irradiation. Further studies should evaluate the role of prophylactic para-aortic irradiation in high-risk patients.

\section{Conclusion}

Although most patients in our study experienced recurrence within 5 years following treatment, our result showed that the EBRT boost in conventional fractionation is valuable in two subgroups of patients including those without regional lymph node metastasis and those with haemoglobin levels above $11 \mathrm{~g} / \mathrm{dl}$.

\section{Acknowledgements}

We would like to thanks Dr Abdelouahed ER-RAKI, head of archive and cancer registry unit of National Institute of oncology, for allowing us to access patients' data.

\section{Conflicts of Interest}

The authors declare no conflicts of interest regarding the publication of this paper.

\section{References}

[1] Viswanathan, A.N., Thomadsen, B., American Brachytherapy Society Cervical Cancer Recommendations Committee, American Brachytherapy Society (2012) American Brachytherapy Society Consensus Guidelines for Locally Advanced Carcinoma of the Cervix. Part I: General Principles. Brachytherapy, 11, 33-46. https://doi.org/10.1016/j.brachy.2011.07.003

[2] Haas, J.A., Witten, M.R., Clancey, O., Episcopia, K., Accordino, D. and Chalas, E. (2012) CyberKnife Boost for Patients with Cervical Cancer Unable to Undergo Brachytherapy. Frontiers in Oncology, 2, 25. https://doi.org/10.3389/fonc.2012.00025

[3] Barraclough, L.H., Swindell, R., Livsey, J.E., Hunter, R.D. and Davidson, S.E. (2008) External Beam Boost for Cancer of the Cervix Uteri When Intracavitary Therapy Cannot Be Performed. International Journal of Radiation Oncology, Biology, Physics, 71, 772-778. https://doi.org/10.1016/j.ijrobp.2007.10.066

[4] Matsuura, K., Okabe, T., Fujita, K., Tanimoto, H., Akagi, Y. and Kagemoto, M. (2012) Clinical Results of External Beam Radiotherapy Alone with a Concomitant Boost Program or with Conventional Fractionation for Cervical Cancer Patients Who Did Not Receive Intracavitary Brachytherapy. Journal of Radiation Research, 53, 900-905. https://doi.org/10.1093/jrr/rrs051

[5] Kim, H., Kim, Y.S., Joo, J.H., et al. (2018) Tumor Boost Using External Beam Radiation in Cervical Cancer Patients Unable to Receive Intracavitary Brachytherapy: Outcome from a Multicenter Retrospective Study (Korean Radiation Oncology Group 1419). International Journal of Gynecological Cancer, 28, 371-378. https://doi.org/10.1097/IGC.0000000000001155

[6] Globocan (2018) Summary Statistic 2018. 
http://gco.iarc.fr/today/data/factsheets/populations/504-morocco-fact-sheets.pdf

[7] Saibishkumar, E.P., Patel, F.D., Sharma, S.C., Karunanidhi, G., Sankar, A.S. and Mallick, I. (2006) Results of External-Beam Radiotherapy Alone in Invasive Cancer of the Uterine Cervix: A Retrospective Analysis. Clinical Oncology, 18, 46-51. https://doi.org/10.1016/j.clon.2005.10.004

[8] Ito, K., Shimizuguchi, T. and Karasawa, K. (2019) Clinical Outcomes Following Conventional External Beam Radiotherapy Boost in Japanese Patients with Cervical Cancer Who Are Ineligible for Intracavitary Brachytherapy. Japanese Journal of Clinical Oncology, 49, 270-275. https://doi.org/10.1093/jjco/hyy187

[9] Karlsson, J., Dreifaldt, A.C., Mordhorst, L.B. and Sorbe, B. (2017) Differences in Outcome for Cervical Cancer Patients Treated with or without Brachytherapy. Brachytherapy, 16, 133-140. https://doi.org/10.1016/j.brachy.2016.09.011

[10] Kadkhodayan, S., Homaei Shandiz, F., Seilanian Toussi, M., Afzal Aghaee, M., Farshidi, F. and Dehghan, P. (2013) Concurrent Chemoradiotherapy without Brachytherapy in Locally Advanced Cervical Cancer. Iranian Journal of Cancer Prevention, 6, 195-200.

[11] Haensgen, G., Krause, U., Becker, A., et al. (2001) Tumor Hypoxia, p53, and Prognosis in Cervical Cancers. International Journal of Radiation Oncology, Biology, Physics, 50, 865-872. https://doi.org/10.1016/S0360-3016(01)01523-1

[12] Dunst, J., Kuhnt, T., Strauss, H.G., et al. (2003) Anemia in Cervical Cancers: Impact on Survival, Patterns of Relapse, and Association with Hypoxia and Angiogenesis. International Journal of Radiation Oncology, Biology, Physics, 56, 778-787. https://doi.org/10.1016/S0360-3016(03)00123-8

[13] Münstedt, K., Johnson, P., Bohlmann, M.K., Zygmunt, M., von Georgi, R. and Vahrson, H. (2005) Adjuvant Radiotherapy in Carcinomas of the Uterine Cervix: The Prognostic Value of Hemoglobin Levels. International Journal of Gynecological Cancer, 15, 285-291. https://doi.org/10.1136/ijgc-00009577-200503000-00016

[14] Grogan, M., Thomas, G.M., Melamed, I., et al. (1999) The Importance of Hemoglobin Levels during Radiotherapy for Carcinoma of the Cervix. Cancer, 86, 1528-1536. https://doi.org/10.1002/(SICI)1097-0142(19991015)86:8<1528::AID-CNCR20>3.0.C O;2-E

[15] Kapp, K.S., Poschauko, J., Geyer, E., et al. (2002) Evaluation of the Effect of Routine Packed Red Blood Cell Transfusion in Anemic Cervix Cancer Patients Treated with Radical Radiotherapy. International Journal of Radiation Oncology, Biology, Physics, 54, 58-66. https://doi.org/10.1016/S0360-3016(02)02896-1

[16] Bishop, A.J., Allen, P.K., Klopp, A.H., Meyer, L.A. and Eifel, P.J. (2015) Relationship between Low Hemoglobin Levels and Outcomes after Treatment with Radiation or Chemoradiation in Patients with Cervical Cancer: Has the Impact of Anemia Been Overstated? International Journal of Radiation Oncology, Biology, Physics, 91, 196-205. https://doi.org/10.1016/j.ijrobp.2014.09.023

[17] Bhatla, N., Berek, J.S., Cuello Fredes, M., et al. (2019) Revised FIGO Staging for Carcinoma of the Cervix Uteri. International Journal of Gynecology \& Obstetrics, 145, 129-135. https://doi.org/10.1002/ijgo.12749

[18] Cheng, X., Cai, S., Li, Z., Tang, M., Xue, M. and Zang, R. (2004) The Prognosis of Women with Stage IB1-IIB Node-Positive Cervical Carcinoma after Radical Surgery. World Journal of Surgical Oncology, 2, 47.

https://doi.org/10.1186/1477-7819-2-47

[19] Okazawa, M., Mabuchi, S., Isohashi, F., et al. (2012) The Prognostic Significance of Multiple Pelvic Node Metastases in Cervical Cancer Patients Treated with Radical 
Hysterectomy plus Adjuvant Chemoradiotherapy. International Journal of Gynecological Cancer, 22, 490-497. https://doi.org/10.1097/IGC.0b013e31823c369b

[20] Mahmoud, O., Kilic, S., Khan, A.J., Beriwal, S. and Small, W. (2017) External Beam Techniques to Boost Cervical Cancer when Brachytherapy Is Not an Option-Theories and Applications. Annals of Translational Medicine, 5, 207.

https://doi.org/10.21037/atm.2017.03.102

[21] Jorcano, S., Molla, M., Escude, L., et al. (2010) Hypofractionated Extracranial Stereotactic Radiotherapy Boost for Gynecologic Tumors: A Promising Alternative to High-Dose Rate Brachytherapy. Technology in Cancer Research \& Treatment, 9, 509-514. https://doi.org/10.1177/153303461000900509

[22] Cihoric, N., Tsikkinis, A., Tapia, C., Aebersold, D.M., Zlobec, I. and Lössl, K. (2015) Dose Escalated Intensity Modulated Radiotherapy in the Treatment of Cervical Cancer. Radiation Oncology, 10, 240. https://doi.org/10.1186/s13014-015-0551-0

[23] Nivet, A., Schlienger, M., Clavère, P. and Huguet, F. (2019) Effects of High-Dose Irradiation on Vascularization: Physiopathology and Clinical Consequences. Cancer Radiotherapie, 23, 161-167. https://doi.org/10.1016/j.canrad.2018.05.009

[24] Morris, M., Eifel, P.J., Lu, J., et al. (1999) Pelvic Radiation with Concurrent Chemotherapy Compared with Pelvic and Para-Aortic Radiation for High-Risk Cervical Cancer. The New England Journal of Medicine, 340, 1137-1143. https://doi.org/10.1056/NEJM199904153401501

[25] Eifel, P.J., Winter, K., Morris, M., et al. (2004) Pelvic Irradiation with Concurrent Chemotherapy versus Pelvic and Para-Aortic Irradiation for High-Risk Cervical Cancer: An Update of Radiation Therapy Oncology Group Trial (RTOG) 90-01. Journal of Clinical Oncology, 22, 872-880. https://doi.org/10.1200/JCO.2004.07.197

[26] Meng, Q., Liu, X., Wang, W., et al. (2019) Evaluation of the Efficacy of Prophylactic Extended Field Irradiation in the Concomitant Chemoradiotherapy Treatment of Locally Advanced Cervical Cancer, Stage IIIB in the 2018 FIGO Classification. Radiation Oncology, 14, 228. https://doi.org/10.1186/s13014-019-1431-9

[27] Wang, W., Liu, X., Meng, Q., Zhang, F. and Hu, K. (2018) Prophylactic Extended-Field Irradiation for Patients with Cervical Cancer Treated with Concurrent Chemoradiotherapy: A Propensity-Score Matching Analysis. International Journal of Gynecological Cancer, 28, 1584-1591.

https://doi.org/10.1097/IGC.0000000000001344 